\title{
La ancestralidad en el género y lenguaje literarios en Changó, el gran putas y Sortilégio II
}

Ancestral Memories in Gender and Literary Language in Chango, El Gran Putas and Sortilegio II

\section{Denilson Lima Santos ${ }^{1}$}

Universidad de Antioquia, Medellín, Colombia

denilsonlimas@gmail.com

\section{RESUMEN}

En este ensayo planteamos el texto literario como un espacio de reescritura de las tradiciones yorubas y bantúes como fuerza motriz creadora de un discurso literario. Las voces africanas en las Américas aparecen recuperadas en un modelo estético diferente al hegemónico. Como ejemplo de eso, se propone describir las obras Sortilégio II: mistério negro de Zumbi redivivo (1979), de Abdias do Nascimento (1914-2011), y Changó, el gran putas (1983), de Manuel Zapata Olivella (1920-2004). Los autores de estas obras, como intelectuales, se posicionan como insurrectos, como conscientes de las voces heterogéneas que habitan el mundo afrolatino y ponen esas voces como parte de la estética de sus textos. Así, los intelectuales afrolatinos proponen una escritura de la ancestralidad afro con propósitos estéticos y políticos en la tradición literaria latinoamericana.

\section{PALABRAS CLAVE}

Escritura, tradiciones africanas, literatura, lenguaje, ancestralidad

\section{ABSTRACT}

In this essay we propose the literary text as a space for the re-writing of Bantu's and Yoruba's traditions like a creative motor force of literary discourse. African voices in the Americas appear to regain power in a different, aesthetic,

1 Estudiante del Programa de Doctorado en Literatura de la Universidad de Antioquia, de Medellín (Colombia). Miembro del Grupo de Estudios de Literatura y Cultura Intelectual Latinoamericana (Gelcil). Becado por la fundación CAPES, Ministerio de Educación de Brasil, proceso número 19036/12-4. 
hegemonic model. An example of this can be seen in the literary works: Abdias do Nascimento's (1914-2011) Sortilégio II: mistério negro de Zumbi redivivo (1979) and Manuel Zapata Olivella's (1920-2004) Changó, el gran putas (1983). The authors of these works, as intellectuals, position themselves as rebels, conscious of the heterogeneous voices that inhabit the Afro-Latin world and they give those voices a role in the aesthetics of their texts. Thus, these intellectuals propose an Afro-Latin writing of African ancestry with aesthetic and political purposes in the Latin American literary tradition.

\section{KEYWORDS}

Writing, African traditions, Literature, Language, Ancestry

\section{Comencemos}

El paulista de Franca, Abdias do Nascimento, hijo de Georgina Ferreira do Nascimento (ama de casa y modista) y José Ferreira do Nascimento (zapatero), estuvo en defensa de la cultura e igualdad para las poblaciones afrobrasileñas. Su participación en la sociedad fue importante, puesto que reflexionó sobre la actividad y la cuestión del negro en Brasil. También participó de la vida política y cultural. Fundó en 1944 el Teatro Experimental Negro, fue miembro de la Frente Negra Brasileña: movimiento negro extinto por la dictadura del gobierno de Getúlio Vargas en la década de 1930. También fue diputado federal (1983-1987) y senador de la República (1997-1999). Además de eso, en 1978 fundó el Movimiento Negro Unificado y propuso con éxito el 20 de noviembre como Día de la Conciencia Negra en la ciudad de São Paulo. Su obra comprende un extenso listado de publicaciones, entre las cuales podemos mencionar O Griot e as Muralhas (2006), Quilombo: Edição em fac-símile do jornal dirigido por Abdias do Nascimento (2003 [1948-1950]), O quilombismo (2002 [1980]), O Brasil na Mira do Pan-Africanismo (2002), Orixás: os Deuses Vivos da África (1995) y Sortilégio Il: mistério negro de Zumbi redivivo (1979 [1957]).

Con una vida dedicada a las artes y a la militancia política, podemos afirmar que el intelectual afrobrasileño asume el papel de líder de su gente, y aquí aludimos al rol mítico de Changó, el Oricha de la emancipación, de la justicia y de la retórica. Abdias do Nascimento es un escritor que - por medio de su activismo político y literario-cumple en la sociedad de Brasil la función de convocar a las negras y a los negros a seguir en la lucha por una liberación plena. Su escritura es la fijación de las culturas yoruba y bantú en la estética latinoamericana, y esto hace que el legado ancestral sea elemento de su teatro, ensayo y poética. 
El loriqueño Manuel Zapata Olivella, hijo de Edelmira Olivella (ama de casa) y Antonio María Zapata Vásquez (profesor), es considerado un relevante autor, por exponer en sus obras una forma de las identidades negras, teniendo en cuenta el encuentro del afro con el mestizo y el indígena. Desde su juventud empezó a escribir en el periódico El Fígaro, y en las revistas Estampa de Bogotá, y Cromos, Sábado y Suplemento Literario de El Tiempo. Además de eso, el autor negro colombiano tuvo una extensa creatividad literaria, entre las que cabe destacar Tierra mojada (1947) y Calle 10 (1960), en la que no se ocupó solamente de la temática afro. La problemática mitificada de los negros de América es abordada en Chambacú, corral de negros (1963), Chimá nace un santo (1963) y Changó, el gran putas (1983).

Más allá de la fe, a la literatura le concierne el reinventar lo sagrado, como en el alabado del epígrafe que indica que los ancestros guían en el destino y el hombre puede reordenar su camino. Tal vez con esta idea se pueda visibilizar lo más curioso, lo más impresionante, de la lectura de las obras de Manuel Zapata Olivella. En ellas se percibe la conciencia de ser en el mundo y la recuperación del ciclo ancestral en otras tierras. Sin duda, Zapata Olivella es el sortilegio de Colombia en el sentido de jugar con la escritura y recuperar el valor de las tradiciones culturales de su país. Más allá de una manifestación cultural yoruba y bantú que se encontraba en los cantos, las danzas y los cuerpos de los negros y las negras colombianos estaban saberes ancestrales, que componen las líneas de su escritura como los hilos de una tela con dibujos y mensajes africanos.

Por lo que se ha planteado hasta aquí y para mencionar más detenidamente las cuestiones de los géneros y lenguaje literarios, a partir de una mirada a la escritura ancestral y la intelectualidad afro, fueron escogidas dos obras con sus respectivos autores: Sortilégio Il: mistério negro de Zumbi redivivo (1979), de Abdias do Nascimento (Franca, 1914-Río de Janeiro, 2011) y Changó, el gran putas (1983), de Manuel Zapata Olivella (Lorica, 1920-Bogotá, 2004). Esta selección tiene en cuenta comparar la manera en que ellos reescriben las tradiciones bantúes y yorubas, posicionándose como intelectuales que recuperan estas tradiciones en el plano estético y político. Igual que Manuel Ruy en la crónica citada anteriormente, los autores afrolatinoamericanos hacen de su escritura un arma de lucha. Son sus palabras una herramienta para incomodar a aquellos que insisten en invisibilizar la episteme afro tan desbordada de ancestralidad.

Cuando hablamos de África, ¿a qué África estamos refiriéndonos? Es una cuestión fundamental para plantear el lugar de las literaturas africanas. La pluralidad de culturas tradicionales que fueron colonizadas y estuvieron bajo el poder del europeo, aparecen hoy en la amplia literatura que 
podemos nombrar de expresión española, portuguesa, inglesa, francesa, para poner como adjetivo la lengua oficial, que es la herencia impuesta por el colonizador. Además de ello, hubo pueblos que resistieron a la colonización y siguieron con sus tradiciones orales. En este contexto de oratura - el texto oral de los pueblos tradicionales del continente africano- versus la escritura occidental, para que seamos objetivos, miramos a los pueblos del otro lado del Atlántico que fueron colonizados por portugueses y españoles; a saber, los países que hablan el portugués como lengua nacional: Angola, Mozambique, Guinea-Bisáu, Santo Tomé y Príncipe, Cabo Verde. Del mismo modo el que tiene como lengua nacional el español (en este caso, Guinea Ecuatorial). Lo más importante en este ensayo es observar los puntos comunes entre los objetos de estudio, específicamente Abdias do Nascimento y Manuel Zapata Olivella, junto con autores y autoras de África, en el contexto de apropiación del sistema alfabético occidental para producir sus textos. De ahí, queremos observar cómo los autores africanos usan la misma estrategia de, por medio de la literatura, insertar en la estética universal los valores de sus tradiciones ancestrales.

\section{Una escritura ancestral}

Los géneros literarios son prácticas discursivas, culturales y están cargados de imaginarios múltiples que pueden reflexionar con profundidad el diálogo crítico de la propia creación literaria con otras prácticas sociales, y no pierden el conjunto sémico y poético, como asevera Julia Kristeva (2005). En sentido del texto como discursividad literaria, es decir, como espacio de creación discursiva, se puede pensarlo como subversión estética, algo que es muy recurrente en los tiempos modernos. Los autores afrolatinoamericanos Abdias do Nascimento y Manuel Zapata Olivella establecen una escritura que funciona como una recreación de la ancestralidad bantú y yoruba bajo el signo de la escritura insurgente. En verdad, tanto el autor brasileño como el colombiano hacen un reclamo a la invisibilización del aporte africano en la modernidad. Es en este sentido que se piensa la subversión, puesto que la estética hegemónica no tenía en cuenta las voces heterogéneas de los afros. De esta manera, el aporte que las tradiciones africanas pueden contribuir para la sociedad está más allá de representaciones folclóricas; es necesario mirar hacia la profundidad de la oralitura africana, que está resonada en la estructura textual de los dos escritores. Más bien, ¿cómo los autores se apropian de los géneros literarios occidentales y los redimensionan con estructuras y matices africanos? O podríamos plantear otros interrogantes para reflexionar sobre el estilo y proyecto estético de los intelectuales afros. Ellos escriben en el lenguaje del colonizador y subvierte este lenguaje. De ahí, preguntamos: ¿cómo los escritores afro se apropian del lenguaje del amo? ¿Sus escrituras utilizan el 
estilo afro? ¿De qué manera demuestra en el discurso literario la identidad afro? ¿Cómo los escritores o escritoras, a partir de la identidad afro, recupera la cosmovisión de mundo de su etnia?².

Ahora bien, la idea de género literario - a partir de una lógica grafocéntrica del pensamiento europeo para cotejar con estructuras poéticas africanas-, "que se tem em vista aqui não exige, porém, nenhuma mudança de mentalidade, antes, força a mesma mentalidade a orientar-se por um novo objetivo, essencialmente diverso do antigo» (Lukacs, 2000, p. 37). La estructura de la escritura occidental es utilizada por los intelectuales afrolatinoamericanos y no presenta cambios en su utilización; sin embargo, en la cuestión de la manera de escribir, hay una transformación estética. En otros términos, las tradiciones bantúes y yorubas presentes en la escritura de Abdias do Nascimento y Manuel Zapata Olivella son reorientadas como materia de la escritura; es claro que esta episteme de corte africano está en el contexto del pensamiento occidental y utiliza el sistema alfabético europeo para ganar visibilidad. De ahí, el mundo, el muntu, está ahora reconfigurado, roto, fragmentado, más bien transculturado en la frontera de la oratura, escritura y performance. Lo que una novela de Zapata Olivella propone es reubicar la humanidad perdida bajo la trata y el colonialismo; esto es, el escritor afro colombiano performatiza, trae al texto la virtualidad de las culturas africanas en la diáspora y las reinventan en una «actualidad» (Zumthor, 2007, p. 31). Hay, en la obra, la discursividad literaria de los hechos históricos como un acto comunicativo; así se puede ver en el principio del capítulo, «La trata»:

La fortaleza nació entre la orilla del mar y la barranca del río, pequeña, perdida en la costa. Al principio la loba blanca trae unos cuantos ekobios encadenados que no hablaban nuestras lenguas. Desembarcaron fusiles, cañones y barriles de alimento. Asombrados y recelosos vimos crecer sus murallas y casamatas blancas para que el muntu se pudra por dentro (Zapata Olivella, 2010a, p. 182).

Nótese que el escritor describe el ambiente que historiadores y antropólogos ya señalaron como espacio donde los europeos ajuntaban a los negros africanos (los puertos en África donde llegaban los esclavos, por ejemplo, en Guinea-Bisáu, en Benguela, Angola), lo que era una cuarentena, para después traerlos hasta las Américas. El narrador en esta parte de la historia se reconoce como ekobio, es decir, compañero de viaje, como

2 Es imprescindible observar que, en la literatura africana contemporánea, cuestiones como las que hicimos arriba están resueltas en la estética literaria de los escritores y escritoras. Por ejemplo, en las obras de Odete Semedo (Guinea-Bisáu), Entre o ser e o amor (1996); de Chimamanda Ngozi Adichie (Nigéria), Americanah (2014); de Amalia Lú Posso Figueroa, Vean ve, mis nanas negras (2013), entre otras. 
esclavizado, prisionero; pero le parecen extraños otros «hermanos» que no tienen el mismo código lingüístico y «no hablan nuestras lenguas». Zapata Olivella hace una relectura de la trata africana y resalta las tensiones discursivas. En la visión de la alteridad textual, el otro aparece igual al yo (en situación de esclavitud) y, al mismo tiempo, diferente al yo (habla otro código lingüístico). Sin embargo, en otra espacialidad (las Américas), la diferencia no será un entrabe, puesto que las tradiciones se recuperarán de manera solidaria, sin perder la idiosincrasia, por supuesto.

Al contrario de la imposición de la cultura escrita a los aborígenes de las Américas (Lienhard, 2003) o en el comienzo de la heterogeneidad en la cultura andina (Cornejo Polar, 2003), el colonizador, a saber, la Loba Blanca, construye el «Fuerte» $y$, dentro de sus murallas, las culturas africanas tienen su primer encuentro. Se puede afirmar que las heterogeneidades afrolatinas empiezan en África, en el espacio de confinamiento: las etnias eran diferentes, los códigos lingüísticos eran distintos, pero los negros estaban bajo el mismo signo: esclavitud-extrañamiento. Sin lugar a dudas, la oralidad en aquel momento era el único estatuto de diferencia entre los africanos, además de sus marcas corporales que indicaban el origen étnico. De hecho, debido a las lenguas diferentes, los pueblos con sus peculiaridades están, a partir del momento de la captura y trata, condenadas a hacer un juego de cultura, un encuentro de saberes, pero no una yuxtaposición, como ya señaló Zapata Olivella (1989, p. 13).

Con los fusiles y las pólvoras para matar al otro: así empieza el encuentro de Occidente con África. El corpus africano que se inyecta a la escritura. De verdad, la cultura yoruba y bantú en América Latina es una adaptación similar a la realizada por los escritores africanos en África. Primero se vive en la cultura y después es recuperada tanto por Zapata Olivella como por Nascimento en la escritura. El hecho significativo del punto de vista de la estética literaria es que las huellas de africanía son adaptadas y recuperadas en la escritura por medio de la discursividad ancestral.

Es cierto que las poblaciones africanas no trajeron la escritura, en sentido grafocéntrico, pero sus cuerpos eran el lugar donde se guardaba el registro, la grafía visible de la identidad. Cada señal étnica podía ser leída por los otros y, de esta manera, se reconocían y se identificaban a partir de los símbolos, que eran inscripciones corporales. Llamaremos a esta manera de identificación corporal de cuerpo-escritura, pues no solo los símbolos en el cuerpo indicaban una pertenencia, sino representaban el conocimiento traído en la memoria, en los gestos, la musicalidad, las danzas, y que son reinventados en la escritura alfabética. El cuerpo-escritura es parte de la discursividad literaria, una vez que reinventa la tradición yoruba y bantú como materia estética de la palabra escrita. Un ejemplo 
de lo que hemos planteado hasta aquí ocurre cuando la sacerdotisa en Sortilégio /l predice lo que ocurrirá en el futuro con Emanuel:

IYALORIXÁ

Distingo ainda pedras na colina... parecem grandes seios... sim... é Abeocutá... peitos de Yemanjá pingando leite... escorrendo todas as águas... Águas correndo... rio Ogun se fazendo... fazendo (Novo silêncio, joga novamente o opelê) Parece que ainda há mais... Sim, os Eguns... também estarão presentes... Vão dançar o festival da passagem (Nascimento, 1979, p. 47).

El cuerpo dilatado. La lectura está más allá de lo que se muestra. El mito de Yemayá sostiene que es la grande madre y que de sus senos nacen dos ríos en África, en la tradición yoruba. O el Oricha Ogún que se transcultura, es decir, es recreado en nuevas significaciones. Es el juego de la vida, puesto que la muerte (representada por los Eguns) es símbolo de la continuidad, esto es, la concepción yoruba de los mundo ará-ayié (mundo físico) y ará-orum (mundo abstracto, espiritual, no hay una localización). El orum «é um mundo abstrato e paralelo ao mundo real que coexiste com todos os conteúdos deste» (Elbein dos Santos, 1986, p. 54). En realidad, la sacerdotisa asume el rol del griot y traduce la cosmovisión en nuevo espacio, nuevo tiempo. La episteme africana reinventada en la diáspora se torna el cuerpo-escritura en la obra de los escritores afrolatinoamericanos, permitiendo las experiencias individuales como escritura colectiva. La cosmovisión africana reiterada por los mayores resurge en la escritura de Abdias do Nascimento en el punto de tensión, en la transculturación de la palabra escrita. En otros términos, la tradición oral invadió la escritura alfabética occidental, resignificando los símbolos (musicalidad, léxico, inscripciones corpóreas, danzas, entre otros). Lo que hace el intelectual afrobrasileño es, por medio de la discursividad literaria, conjugar la estética con la estructura de la oralitura afro (la teogonía yoruba en la obra teatral, por ejemplo), en plan no solo de la cultura sino en la reestructuración de la escritura alfabética occidental. Es como si el literato permanentemente estuviese diciendo en su escritura: «[v]oy a minar el arma del otro con todos los elementos posibles de mi texto» (Ruy, 1987, p. 310); esta es la cuestión central de la insurrección de la tradición literaria afrolatina. Los intelectuales afros dinamitan la escritura alfabética del colonizador. Lo importante es reescribir las tradiciones africanas en la diáspora, texto bajo el signo de la episteme que está presente en la discursividad de la ancestralidad, es decir, conformar un discurso que visibilice las voces yoruba y bantú en la estética literaria latinoamericana. 


\section{Reescrituras de las tradiciones africanas}

Es posible que la transculturación en el teatro de Nascimento se acerque a lo que ocurrió con el teatro africano. «Africa is home to several traditions of theater, conceived as an ensemble of culturally marked and consciously staged practices in space and time and before an audience. Many of these traditions are of ancient origin, while others emerged with formal European colonization of the continent in the nineteenth century and the subsequent imposition of western education, religion, and culture» (Olaniyan, 2007, p. 353). Las tradiciones más antiguas preservan la lengua africana autóctona. En el proceso transcultural, el arte tradicional gana nuevos aspectos, como escenario, figurinos, entre otros elementos. Además de esto, hay, en África moderna, la cuestión del público que paga para disfrutar de una escenificación teatral, pues antes del colonialismo era inexistente que un ciudadano pagara para ello. Lo que queremos resaltar es que en un contexto amplio, Sortilégio /l puede ser interpretado como movimiento anticolonial, puesto que rescata el papel del sujeto negro como productor de su arte. En este sentido, la transculturación de las tradiciones yoruba y bantú es eminentemente política, tal cual el teatro de desenvolvimiento africano.

Por lo anterior, es importante ver que el texto, entonces, performatiza las tradiciones africanas. Abdias do Nascimento y Manuel Zapata Olivella hacen el juego de la escritura con la oralitura. Los conocimientos de las tradiciones africanas, sobre todo por la religiosidad, son importantes para que la escritura tenga aportes de la oralidad heredada de los pueblos transatlánticos.

En el apartado «El muntu americano» de Changó, el gran putas, el narrador, en la persona del tío Domingo, narra el nacimiento demorado de Benkos Biohó: el niño que resistía en nacer, causando el sufrimiento a la madre, y necesitaba de ayuda, no en sentido físico, sino en la esfera espiritual, más bien, ancestral. Como revela el narrador, al llegar al lugar donde estaba la mujer en trabajo de parto:

Me voy derecho al rincón donde se apretaban los espantos ahogados por el humo de un candil. Encuentro el menjurje de las plantas aromáticas sobre el vientre, la baba sanguinolenta que escupe la matriz y el grito acongojado de la parturienta en medio de las siete comadronas: la mandinga, la del país Yolofo, dos del Manikongo y las de Angola, el Calabar y Cabo Verde.

- No hemos podido sacarle el muchacho - aclara la más anciana en lengua bantú (Zapata Olivella, 2010 a, p. 154).

En la escritura de Zapata Olivella, es posible denotar el cuerpo-escritura africano que permite a la discursividad literaria resaltar la episteme 
ancestral. En primer plano, está evidente el sistema alfabético del colonizador; sin embargo, otros signos tejen el texto y le permiten una lectura diferente. Es posible observar el encuentro de tradiciones, los pueblos africanos reunidos en el nacimiento de aquel que traería el aliento de la permanente lucha por la libertad. El escritor afrocolombiano adjunta a su historia el encuentro de las mayores, es decir, las abuelas, las mujeres que detenían el conocimiento. La Mandinga, la Yolofo, la Manikongo, las de Angola, Calabar y Cabo Verde representan el saber ancestral, la voz femenina que trae la vida, los que van a nacer. Es importante observar que, en la construcción de las tradiciones africanas en la diáspora, los pueblos africanos que supuestamente eran separados por lenguas, culturas o religiones ahora están reunidos bajo un solo propósito: la reescritura de sus tradiciones en estas tierras, sin dejar la heterogeneidad. Como ya señalamos, los pueblos africanos en las Américas reinventan la episteme ancestral, la cual permite al intelectual afrocolombiano hacer la relectura de las tradiciones yorubas y bantúes en su obra. De ahí es que, aunque no aparezca en la grafía bantú, la palabra de la anciana que expone el problema es el saber oral que se escucha. Más allá de ello, frente a tal hecho de dificultad del nacimiento, tío Domingo ya tiene en mente lo que es necesario hacer: recurrir a su conocimiento ancestral:

Me puse a levantar los escapularios y abro una rendija para que entraran los ancestros: primero Sosa Illamba, partera del nuevo muntu. Le traía las sangres y las aguas de los buenos partos. Después Nagó le descose los párpados para encenderle las chispas de la guerra. Lento, pisadas grandes, se acercó Olugbala. Para agrandar la brecha de la matriz, mete un hombro, luego el otro y ya adentro, palmoteó por tres veces las nalgas del niño infundiéndole su potencia. Huyó la oscuridad porque se acerca el sol de Kanuri mai, la sonrisa que soporta todos los dolores. Ausente, presente, también estuvo el abuelo Ngafúa, dador de la experiencia (Zapata Olivella, 2010a, p.155).

¿Cómo aparece, entonces, el cuerpo-escritura en la discursividad literaria de Zapata Olivella? En el primero se observa la integración de elementos culturales: escapulario (que había sido regalado por el padre Claver) y los ancestros que faltaban en la reunión del nacimiento: «Sosa Illamba, Nagó, Olugbala, Kanuri mai». No era posible el nacimiento si no hubiese la presencia de la continuidad ancestral. Tal hecho hace crecer a la leyenda de Ochún ${ }^{3}$, que, por no ser invitada para la ceremonia con los otros

3 «Quando todos os orixás chegaram a terra, organizaram reuniões onde as mulheres não eram admitidas. Oxum ficou aborrecida por ser posta de lado e não poder participar de todas as deliberações. Para se vingar, tornou as mulheres estéreis e impediu que as atividades desenvolvidas pelos deuses chegassem a resultados favoráveis. Desesperados, os orixás 
orichas, no permitió que la tierra, las mujeres y los animales generasen descendencia. En la lectura afrorreligiosa, no hay camino que sea seguro si allá no están los ancestros. En la escritura de Zapata Olivella el repertorio del lenguaje evoca las tradiciones bantúes como lenguaje que se realiza, que hace la travesía donde el cuerpo (de la madre, del hijo) es metáfora del muntu en la diáspora; es decir, el cuerpo, las palabras, los ritos están en un continuo «processo de deslocamento e de ressignificação, torna-se ele próprio uma geografia, uma paisagem, um território de linguagens, um continente sem fim trespassado de palabras» (Martins, 2013, p. 68). De ahí, es posible que las poéticas orales aparezcan como performances textuales permeadas por símbolos que son recreados en la escritura a fin de recuperar el conocimiento milenario africano. El sentido discursivo es hacer una tesitura fluyente, con los aportes de la cultura bantú y, por supuesto de las tradiciones como yolofo, mandinga, manikongo, entre otras, que son los sustratos lingüísticos que desmontan el texto y la estética hegemónica eurocéntrica. En este sentido, la tradición afro se ocupa de la discursividad literaria, es decir, de reinventar las tradiciones africanas bajo el signo de la palabra, que está cargada del corpus ancestral.

Ahora bien, para que se pueda pensar una escritura que dé cuenta de una estética en contra del orden hegemónico, el escritor afrolatinoamericano, como un intelectual que recupera su cultura bantú y yoruba, teje de manera simbólica lo que Daiana Taylor (2014) Ilama memoria de archivo; es decir, la escritura «mantiene un núcleo perdurable: registros, documentos, textos literarios, restos arqueológicos y huesos que supuestamente son resistentes al cambio» (p. 6). Sin embargo, Abdias do Nascimento y Manuel Zapata Olivella no presentan resistencia al cambio; más bien, ellos reescriben sus culturas utilizando los registros y la memoria de sus tradiciones africanas, recreándolas en la tradición alfabética occidental. Ya fue demostrado anteriormente con los encuentros de las tradiciones y la metáfora de la ancestralidad en la figura del tío Domingo, en Changó, el gran putas. Ahora, se hace importante observar cómo la discursividad ancestral utiliza la reescritura de «restos arqueológicos» en la obra Sortilégio II, teniendo en cuenta el cuerpo-escritura yoruba y bantú. En el movimiento, o escena, cerca del epílogo, Emanuel, personaje que ya venció el conflicto

dirigiram-se a Olodumaré e explicaram-lhe que as coisas iam mal sobre a terra, apesar das decisões que tomavam em suas assembleias. Olodumaré perguntou se Oxum participava das reuniões e os orixás responderam que não. Olodumaré explicou-lhes então que, sem a presença de Oxum e do seu poder sobre a fecundidade, nenhum de seus empreendimentos poderia dar certo. De volta a terra, os orixás convidaram Oxum para participar de seus trabalhos, o que ela acabou por aceitar depois de muito lhe rogarem. Em seguida, as mulheres tornaram-se fecundas e todos os projetos obtiveram felizes resultados» (Fatumbi Verger, 2002, p. 67). 
interno de no aceptación de su origen negro-brasileña, revela en sus palabras la interpretación cultural de la tradición religiosa yoruba:

\section{EMANUEL}

Em meu peito, oh Oxumarê! Cintila o reflexo de teu brilho... Serpente que arcoirisa este céu de meia-noite, gerador de maravilhas minhas... que na minha noite busquei e me foram doadas... Neste silêncio absoluto que somente eu percebo... às presenças fundamentais que apenas meus olhos distinguem... Proclamo... Celebro... (Nascimento, 1979, p. 135).

La poesía del texto de Nascimento recupera la memoria guardada en las tradiciones bantúes y yorubas recreadas en el espacio religioso. La palabra performatiza el conocimiento pasado en la comunidad terreiro. El juego de «brilho» y «arcoirisa» (brillo y volver el cielo igual a un arcoíris) reporta a la leyenda yoruba del Oricha Ochumaré, que es la representación del cambio, de las novedades: seis meses es una serpiente y seis meses es un arcoíris que lleva el agua para el castillo de Changó. La escena es la recreación del «archivo de la memoria» (Taylor, 2014, p. 6) que ahora utiliza la escritura como herramienta para que no haya olvido de la oralitura heredada de los antepasados que llegaron aquí con un corpus en sus cuerpos. De ahí, Nascimento reinventa las tradiciones africanas tejiendo una obra rellena del cuerpo-escritura yoruba y bantú, es decir, el lenguaje que reinventa lo africano para permitir en la escritura la estética ancestral. La episteme presentada por el intelectual afrobrasileño es la recreación de las filosofías bantúes y yorubas en encuentro de la discursividad literaria.

Sobre la filosofía bantú, se hace oportuno comprender cómo es la cosmovisión del pueblo tan importante para el pensamiento afro. Para hacer un cuadro comparativo de la ancestralidad demostrada en las obras Sortilégio Il y Changó, el gran putas, nos apoyaremos en el pensamiento bantú. Según Eduardo Oliveira, la Fuerza Vital bantú no es solamente un atributo humano, sino de todo lo que tiene vida. El universo africano es concebido como integrado y los elementos que lo constituyen son independientes. Entonces, para que pueda haber una integración o conexión, es fundamental que todos los seres estén animados por la Fuerza Vital. En otros términos, «a concatenação dos seres no movimento de integração é já o que chamamos de energia fundamental da vida: a Força Vital» (Oliveira, 2006, p. 115). La vida, en suma, solo es posible en conexión, en concatenación con otros seres. La Fuerza Vital es igual a la idea de Aché de la filosofía yoruba. Así, para que se entienda cómo en la escritura de Abdias do Nascimento y de Manuel Zapata Olivella aparece la Fuerza Vital, a continuación se resume el orden de la pirámide vital bantú: 


\section{CUADRO 1}

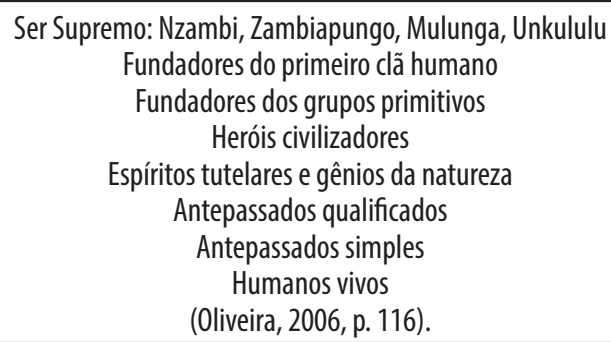

En cuanto al pensamiento yoruba, el Aché o Axé es la fuerza que da movimiento a los seres, tal cual la concepción bantú. Sin embargo, el Aché proviene de los Orichas, que lo recibieron de Olodumare u Olorun, el ser creador de todo. A partir de la lectura del libro Os nagô e a morte (1986), de Juana Elbein Santos, se puede tejer el siguiente resumen con la pirámide del Aché:

\section{CUADRO 2}

Ser supremo, el inaccesible: Olorun, Olodumaré ou Obá-Orun (Rei do òrun) Irumalés (entidades divinas dos primórdios da criação)

Orixás (os quatrocentos da direita)

Ebora (duzentos da esquerda)

Egunguns (espíritos dos mortos)

Ancestrais

Ser humano

(Elbein dos Santos, 1986, pp. 72-101).

Por lo anterior, en la representación yoruba y bantú de Abdias de Nascimento y Manuel Zapata Olivella, estas dos visiones de mundo hacen parte de la discursividad de sus obras. Se aclara aquí que hay una distinción en la visión nagô o yoruba (locumí) entre las dos categorías. A saber: «os orixás, associado a elementos cósmicos ou à natureza, significam matérias simbólicas de origem enquanto os ancestrais significam princípio de existência genérica a nível social» (Ribeiro, 1996, p.166). La cuestión es que el mundo africano recreado en la diáspora juntó los pueblos trasatlánticos en un solo propósito: preservar la tradición ancestral, aunque no estuviesen en los territorios de los ancestros. Tanto en la novela de Zapata Olivella como en el texto teatral de Nascimento, el mundo yorubanto se transcultura y es presentado en dos dimensiones: los ancestros, seres míticos y los antepasados (ancestros a nivel social, o como nombra Zapata Olivella, los padres de la nación). De ahí, para dar continuidad a la raíz del conocimiento milenario, los africanos y sus descendientes utilizaron las más diversas estrategias; entre ellas, crearon espacios llamados terrero, casas, fincas donde pudiesen rendir culto a los Orichas. De esa manera, los dos autores 
se apropian de la cultura escrita colonizadora para fijar en la escritura los hilos de los ancestros que son reinventados en la narrativa de la vida. Sobre esta narrativa, podemos observar lo que Aimé Cesaire postuló sobre la filosofía bantú, contraponiéndola a los intereses y falseamiento científico del colonizador; en específico, a las postulaciones del cura Tempels, que se aprovechó de la idea ontológica de los bantúes haciendo una «trampa» discursiva para legitimar la colonización del Congo. De hecho,

el pensamiento bantú es esencialmente ontológico; que la ontología bantú está fundada en las nociones verdaderamente esenciales de fuerza vital y de jerarquía de las fuerzas vitales; que para el bantú, finalmente, el arden ontológico que define el mundo viene de Dios y, decreta divino, debe respetarse [...] (Cesaire, 2006, p. 30).

Aunque el reverendo belga hubiese hecho un tratado sobre la filosofía bantú, no la respetó suficientemente, la excluyó, la sometió a un sistema de pensamiento colonial que quita de los hombres el derecho a la dignidad. Como afirma Aimé Cesaire, los colonizadores se quitaron el sombrero ante la fuerza vital bantú e hicieron un guiño a la idea de alma inmortal, con el objetivo de que «el dios bantú será garante del orden colonialista belga y será sacrílego todo bantú que ose ponerle la mano encima» (2006, p. 30). El reverendo Tempels usó de artificio el conocimiento de la filosofía bantú como argumento; por supuesto, una justificación para el sometimiento y desarrollo de una psicología de dependencia en el colonizado. El humanismo europeo es excluyente y está desprovisto de alteridad, tal como lo verificó la historia; el colonialismo es prueba cabal de esto. No es necesario irnos lejos para observar el humanismo racista del colonizador europeo. Los autóctonos americanos probaron en su piel tal matanza física y cultural. En dirección opuesta, Do Nascimento y Zapata Olivella tejen la escritura de las tradiciones africanas de manera más discursiva y menos preocupados por el purismo o la autenticidad de las fuentes y el origen. Es una recuperación estética del cuerpo-escritura presente en la tradición oral de los afros en las Américas. En Sortilégio Il y en Changó, el gran putas, la recuperación discursiva de los elementos bantúes y yorubas es, ante todo, un reto político que indudablemente requiere una posición intelectual distinta, descolonizada. De ahí, el patrón estético cambia, pasa de la imposición de una escritura que somete al otro para la oralitura; es la palabra que recupera el otro, el diferente, y el que se reinventa en una ancestralidad desplazada.

En este sentido, la transculturación de las culturas yoruba y bantú está en analogía con el tabaco y el azúcar, como postula Fernando Ortiz (1963, p. 7):

El tabaco nace, el azúcar se hace. El tabaco nace puro, como puro se fabrica y puro se fuma; para lograr la sacarosa, que es el azúcar puro, 
hay que recorrer un largo ciclo de complicadas operaciones fisioquímicas, solo para eliminar impurezas de jugos, bagazos, cachazas, defecaciones y enturbamientos de la polarización.

En cuanto las tradiciones africanas, ellas llegan en estado propios, guardadas en los archivos de la memoria. La escritura se hace, se crea y se fija en los géneros literarios y discursivos. La episteme yoruba y bantú está para el tabaco como la escritura está para el azúcar. Mientras la tradición ancestral africana es negra — nace de la relación entre el hombre y lo sagrado-, la escritura alfabética occidental es blanca y utiliza la estructura lingüística para «eliminar las impurezas», privilegiando una estética en detrimento de otras. De esta manera, la discursividad literaria de Abdias do Nascimento y de Manuel Zapata Olivella insertan en los géneros literarios la novela y el drama: la posibilidad de una escritura insurrecta y dinámica. Insurrecta porque invade el sistema alfabético occidental minándolo con elementos afros. Dinámica porque recupera y reinscribe en la escritura la fecundidad de la cosmovisión yoruba y bantú.

Al comparar las obras aquí estudiadas, se puede observar cómo los dos intelectuales afros utilizan la episteme ancestral para reinventar las tradiciones y fijar en la escritura un discurso literario basado en las pirámides de la ancestralidad yoruba y bantú:

\section{CUADRO 4}

\section{Sortilégio II, o mistério de Zumbi redivivo}

Orixás:

Olokun, yemanjá, xangô, exu, oyá, oxun, ogun, omolú, obaluayê, oxumaré

\begin{tabular}{l} 
Antepasados calificados: \\
Egunguns ou Eguns (os Ancestrais mortos) \\
\hline Fundadores de los clanes: \\
Zumbi de los Palmares (funda o Quilombo \\
no Brasil)
\end{tabular}

Antepasados simples:

La madre de Emanuel

\section{Changó, el gran putas}

Orichas:

Yemayá, changó, ogún, elegba, ochún, oba, oyá

Antepasados calificados:

Bazimu (los muertos), Kanuri Mai

Fundadores de los clanes:

Ngafúa, Kissi-Kama (aún en África), Nagó (el primero que instaura la lucha por la libertad), Benkos Biojó (fundador del primer Palenque colombiano)

Antepasados comúnes:

François Mackandal, Toussaint Louverture, Dessalines, Emperador Christophe, Simón Bolívar, José Prudencio, Padilla, Padre José Maria Morelos, Antonio Maceo, Marcus Garvey, Luther King, Malcolm X, Langston Hughes, Paul Robeson, Richard Wright

Seres vivos: Seres vivos:

lyalorixá (sacerdotisa de (andomblé) Filhas de Santo, Emanuel, Ifigênia
Agne Brown, Burghardt Du Bois, John Brown, la voz narrativa 
A partir del cuadro anterior, el cuerpo-escritura de las tradiciones yorubas y bantúes es conformado en una dinámica entre los ancestrales y los personajes. Mientras Abdias do Nascimento creó personajes para representar las tensiones discursivas y sociales en un Brasil del medio del siglo XX — que rechazaba el elemento cultural afro-, Manuel Zapata Olivella resignificó personajes históricos: Antonio Maceo (1845-1896), Simón Bolívar (1783-1830), entre otros. Esa creación del afrocolombiano no es una casualidad: es el desarrollo del pensamiento yoruba y bantú. Nascimento recupera las figuras literarias, como el personaje Margarida, que aparece en la tradición occidental en Fausto (1808), de Johann Wolfgang von Goethe (1749-1832), o Emanuel, en referencia a la idea judeocristiana de «Dios con nosotros».

En cuanto a los personajes, aunque se trate de obras de géneros diferentes (una pieza teatral y una novela), se puede percibir que tanto Abdias do Nascimento como Manuel Zapata Olivella los conforman de manera compleja. No se percibe que los personajes sean planos, sin complejidades psicológicas, incluso porque la narrativa y el proceso dramático no lo permiten. El tema discursivo de la ancestralidad es utilizado en las dos obras como el hilo que teje la composición de los sujetos. Por un lado, se presentan los embates personales e interpersonales $y$, por el otro, las tensiones discursivas, como se puede ver en Sortilégio Il:

EMANUEL

Violento

Maldita polícia atrás de mim. (pausa breve: Ifigênia sorri) Está rindo... mas sabe que não matei. Você sabe, não sabe? (emoção crescente) Por que não conta tudo? Diga à polícia que não matei Margarida. Olhe: prometo ir morar com você. Não é o que quer? Vamos viver juntos. Nem que seja no rendez-vour da rua Conde Lage... Tenho medo, Ifigênia. Não quero voltar para aquela penitenciária dos infernos... Sabe o que é a cadeia? Anos e anos trancafiado num buraco escuro e frio? (Nascimento, 1979, p. 76).

Emanuel, que huye de su sentencia y está en constante crisis por haber matado a su esposa Margarida, se encuentra perdido y en el desespero promete vivir con Infigênia, su amor, que en la escena lo desdeña. Sin embargo, el personaje promete vivir con ella si lo ayudara: «seja no rendez-vour da rua Conde Lage». En portugués, en sentido popular y con connotación de prejuicio, «rendez-vour» tiene sugerencia de lugar de poco o ningún respeto, casi que un burdel. Se percibe que la complejidad del personaje aparece como prototipo del discurso de no reconocimiento de sus orígenes, algo muy difundido en las poblaciones afro por la clase dominante eurocéntrica brasileña. Como afirma Philip Zwerling en el 
ensayo «The Political Agenda for Theatricalizing Religion in Shango de Ima and Sortilege II: Zumbi Returns» (2004, p. 8), Abdias do Nascimento y, por supuesto, su obra representan «a continuing color-conscious society». Al comparar Sortilégio II y Shangó de Ima (del cubano Pepe Carril), Zwerling postula que las obras teatrales de los autores latinoamericanos están ubicadas bajo las cuestiones políticas, como las relaciones raciales, además de representar la recuperación de la tradición yoruba en las sociedades brasileña y cubana. De manera general, se puede afirmar que Nascimento recupera la conciencia negra y va más allá de un proyecto puramente político-sociológico. Su obra se inserta en una discursividad de la tradición yoruba, es decir, recupera la estética afro en la escritura con el propósito de demostrar no solo el conflicto social, sino el discursivo entre personajes y sociedad.

Para continuar planteando el caso de la recuperación de las tradiciones yoruba y bantú, hacemos una interrogante: ¿cuál es la relación de los personajes y la ancestralidad? En la escritura de las dos obras, los sucesos humanos son concomitantes con los hechos de los seres ancestrales. Ello es perceptible, puesto que la relación Fuerza Vital siempre está resaltada en la escritura; por ejemplo, en Changó, el gran putas, cuando el rey Benkos Biohó es asesinado y los palenqueros, tiempo después, celebran al babalao (el padre, en este caso Biohó) por la semilla de la liberación:

El cadáver del babalao, sombra ausente, nos alumbra. Sabemos que allí arriba, sobre las ramas de la bonga, está acompañado de los Orichas y ancestros. A la medianoche, cuando más encendido esté el lumbalú, bajarán a confundirse con nosotros. Y mientras todo el palenque bailaba, yo palmoteo mi tambor:

¡Alé, lé, lé!

¡Alé, lé, lé!

¡Nadie se sienta esclavo

con la carimba en la nalga,

una noche de cadena

no esclaviza el alma!

(Zapata Olivella, 2010 a, p. 238).

Lo que es relevante aquí es cómo la tradición se reinventa. Cuando Benkos ya no existe, sus súbditos le dedican alabanzas y danzas (como se hace en San Basilio Palenque en el ritual afro del lumbalú). La performance en la escritura recupera la gestualidad, las danzas y la oralidad de los afros, para establecer la discursividad literaria que narre la historicidad del líder palenque. El narrador nos está dando las pistas para entender la complejidad del pensamiento ancestral. Esa composición de los personajes indica que ellos están conectados con el supranatural, es decir, el ancestral, que, en la escritura de Zapata Olivella, denota el devenir de los 
sujetos. El lenguaje oraliturizante compone la escritura con fragmentos de las tradiciones bantúes y yoruba: «los Orichas y ancestros». La escritura está conectada con el cuerpo y voz: se canta y se danza. En este sentido, el intelectual afrocolombiano insurrecciona y dinamiza la tradición alfabética occidental. Benkos Biohó, como «fundador del clan» palenque, es el personaje que recupera las tradiciones yorubas y bantúes en la obra. De hecho, el cuerpo-escritura o, mejor dicho, la episteme de origen afro invade el género literario y le permite nuevos valores de belleza.

Otra cuestión que vale la pena hacer hincapié es el tema del lenguaje y la musicalidad. Se observa en las dos obras las canciones a los ancestros o, cuando mucho, sobre los hechos de los antepasados humanos, incluso como crítica al comportamiento del otro (personaje). De ahí a la moda de la civilizaciones africanas, tanto Abdias do Nascimento como Manuel Zapata Olivella «consideram a palabra ritmada e cantada como poder de vida e de morte, lugar de emergencia de toda a invenção: o nome faz ser, a existência se concebe de ritmo» (Zumthor, 1997, pp. 275-276). Se percibe, entonces, en la escritura, el diálogo con la estructura musical bantú y yoruba, que invade, hace un delito en orden alfabético occidental. Los autores, con la tradición de la oralitura africana, reinventada en la diáspora, tejen sus escrituras en las orillas de la episteme ancestral, donde la gestualidad, la musicalidad y la performance del cuerpo son elementos estructurales tan importantes como los signos lingüísticos.

Para observar más en detalle, se compara con más cercanía las obras a fin a diseñar cómo la canción es herramienta escritural, y los autores la utilizan para configurar la transculturación de los géneros. En Sortilégio II, durante el desarrollo de las escenas, los personajes cantan los «pontos» (en una traducción literal sería «canciones del ritual») para los Orichas. Estas canciones están en lengua portuguesa y reproducen los hechos, las características de los dioses o los rasgos de sus personalidades en forma de alabado:

Ponto de Yemanjá

SOLO: Conchas, búzios, areia fina Palmeiras verdes na campina Rio Ogun, rochas na colina Morada bendita de Janaína

SOLO: Negra sereia de Abeocutá

CORO: Odomi... Odoiá!

SOLO: Águas maternas de Yemanjá

CORO: Princeza de Aiuká!

SOLO: Senhora das ondas

CORO: Da ressaca do mar!

SOLO: Abraça me beija 
CORO: Ao clarão do luar!

SOLO: Oh! Mãe das águas

CORO: Mãe dos peixes

SOLO: Rainha do mar

CORO: Não me deixes

SOLO: Odomi!

CORO: Na loucura de amar

SOLO: Odoceiaba!

SOLO: Ao mar de atirar!

SOLO: Conchas, búzios, areia fina, etc.

(Nascimento, 1973, p. 78).

De igual manera, en Changó, el gran putas es posible observar el uso de los cantos en la narrativa. De ahí, Manuel Zapata atribuye a su escritura la performance del canto basada en las tradiciones africanas, como se puede ver cuando Benkos Biohó dialoga con los ancestros:

— ¡Padre! - lo llama reconociendo al ancestro que sembró su kulonda. El Oricha lo ayuda a subir a su chalupa. Sol y luna juntos en la noche. Le quitó las cadenas que lo aprisionaban y le entrega el sable fundido por Ogún.

—Eres el escogido de Changó para iniciar la rebelión del muntu. Tu grito resonará en otras voces, en otras vidas, donde quiera que la loba blanca pise la sombra de un negro.

Benkos solo responde tres palabras. Si las dijo no lo sé, pero las oigo, las oyeron todos:

- ¡Muera el amo!

¡A-lé, lé-lé!

¡Bumba, musange,

Musangé, é!

Es la hora pensada por Odumare desde los primeros tiempos. En este día, en esta noche, en Cartagena tenías que conjurar al muntu contra los amos (Zapata Olivella, 2010 a, pp. 228-229).

O cuando, en el capítulo «José Prudencio Padilla: Guerras ajenas que parecen nuestras», el personaje Padilla cuenta cómo los otros lo miraban por su posición en el ejército y por su color de piel. En este momento, el canto ancestral es insertado en la escritura en lengua yoruba:

En su arcada principal la bandera del rey ondeaba sobre un escudo de piedra y desde el balcón podían atisbarse los barcos que penetran a la bahía. Los guardias me presentaron armas entre confundidos y asustados. Mi uniforme de contramaestre les asombra solo por el color de mi piel. Siento que he fondeado en la rada de mis ancestros: lyá ma lché lobi, Changó lyá ma lché lobi, Changó Bobo arayé ori Kelé 
lyá ma lché lobi, Changó.

No fue fácil, padre, reencontrar la bahía donde el bunde me calafatea el alma:

¿Quién paga las plumas del eribó?

¡Sangre de un congo bebió el bongó!

(Zapata Olivella, 2010 a, pp. 338-339).

En los textos presentados se perciben encuentros y fusiones de vocablos yoruba y bantú con las lenguas occidentales, portugués y español. Se nota así la recuperación de las tradiciones transatlánticas en la escritura literaria, es decir, el saber ancestral está presente en el lenguaje afro que aportan, en los géneros, las estructuras de la poética y la narrativa ancestral por medio de la discursividad. Es en el sentido de recuperar el saber ancestral que Zapata Olivella recupera los sustratos de las etnias africanas para legitimar una estética basada en la episteme de la ancestralidad. En otros términos, en el contexto de cultura de corte europea, los personajes no pierden el conocimiento afro; por lo contrario, hay una reinvención identitaria de allá, África, que se transcultura aquí, en las Américas.

\section{En búsqueda de conclusiones: no la encontraremos}

Para que se pueda entender los elementos de la tradición oral africana como estrategia de la configuración discursiva de los dos géneros aquí analizados, se propone echar una mirada en un texto de la canción yoruba del culto candomblé de Brasil, recopilado por Altair Bento de Oliveira (2004). Se propone el alabado — que se transcribe abajo — para comparar los sustratos lingüísticos y discursivos como herramientas de apropiación de elementos de la estética hegemónica, sin embargo con influjo de la oralitura afrolatina:

Kíní jé kíní jé olódò Yemonja ó

Ki a sòrò pèléé, ìyá odò ìyá odò (yoruba)

Quem é a dona dos rios? É Yemanja

A quem nos dirigimos expressando simpatia. (tradução ao português) Mãe dos rios, mãe dos rios

(Oliveira, 2004, p. 139).

En este momento, se hace necesario que observemos los elementos de las tradiciones yoruba y bantú en la escritura de Sortilégio ll y Changó, el gran putas: 


\section{CUADRO 5}

\begin{tabular}{|c|c|c|c|}
\hline & Abdias do Nascimento & $\begin{array}{l}\text { Manuel Zapata } \\
\text { Olivella }\end{array}$ & $\begin{array}{l}\text { Recopilación de Altair } \\
\text { Bento de Oliveira }\end{array}$ \\
\hline Yoruba & $\begin{array}{l}\text { Ogun, Yemanjá, Abeocutá, } \\
\text { Aiuká, Odomi, Odoceiaba } \\
\text { Odomi }\end{array}$ & $\begin{array}{l}\text { lyá, Iché, lobi, Changó, } \\
\text { Bobo arayé ori, Kelé }\end{array}$ & $\begin{array}{l}\text { Kíní, jé, olódò Yemonja,Ki, } \\
\text { sòrò pèléé, ìá, odò, ìaá }\end{array}$ \\
\hline Bantú & & $\begin{array}{l}\text { Musange, Bumba, } \\
\text { Mussagé, congo, eribó, } \\
\text { bongó }\end{array}$ & \\
\hline
\end{tabular}

Antes que todo, ya se sabe que las lenguas yoruba y bantú que llegaron a América ganaron variaciones lingüísticas y transformaciones en la lengua portuguesa y en la española. El idioma utilizado por Abdias do Nascimento y Zapata Olivella son reminiscencias de un lenguaje oral que se hablaba en algunas regiones del continente africano en los siglos XIV y XV. Sin embargo, hoy algunos países africanos tienen como lenguas nacionales al quibundo, umbundo o yoruba en sus versiones contemporáneas.

Así, el lenguaje de Abdias do Nascimento y de Manuel Zapata Olivella es como oralitura, la cual se matiza en sus escrituras la «littera, letra, grafa o sujeito no território narratário e enunciativo de uma nação, imprimindo, ainda o neologismo, seu valor de litura, rasura da linguagem, alteração significante, constituinte da diferencia e da alteridade dos sujeitos, da cultura e das suas representações simbólicas» (Martins, 1997, p. 21). En el juego performático de la palabra, los géneros literarios utilizados tanto por Nascimento como por Zapata Olivella ganan resaltos no solo porque es una elección por el modelo de una estética impuesta por el colonizador, sino porque pone en evidencia las heterogeneidades, las reinvenciones de la episteme bantú y yoruba como relieve de otro patrón de mirar y reinterpretar la vida. Ellos desmontan y remontan el cañón del invasor; a saber, la escritura colonizadora, transformando la musicalidad, la palabra como fuerza vital, los conocimientos ancestrales como experiencias individuales y colectivas por medio de la discursividad literaria. 


\section{REFERENCIAS BIBLIOGRÁFICAS}

Césaire, A. (2006). Discurso sobre el colonialismo. Madrid: Ediciones Akal. Cornejo Polar, A. (2003). Escribir en el aire: ensayo sobre la heterogeneidad sociocultural en las literaturas andinas. Lima: Centro de Estudios Literarios Antonio Cornejo Polar.

Elbein dos Santos, J. (1986). Os nagô e a morte: pàde, àsèsè e o culto de Égun na Bahia. Petrópolis: Vozes.

Fatumbi Verger, P. (2000). Notas sobre o culto aos orixás e voduns na Bahia de Todos os Santos, no Brasil e na antiga Costa dos Escravos, na África. São Paulo: Universidad de São Paulo.

Kristeva, J. (2005). Introdução à semanálise. São Paulo: Perspectiva.

Lienhard, M. (2003). La voz y su huella. México D. F.: Casa Juan Pablos.

Lukacs, G. (2000). A teoria do romance: um ensaio histórico-filosófico sobre as formas da grande épica. São Paulo: Duas Cidades \& Ed. 34.

Martins, L. (1997). Afrografias da memória: o reinado do Rosário no Jatobá. Belo Horizonte: Mazza.

Nascimento, A. (1961). Dramas para negros e prólogos para brancos. Antologia de teatro negro-brasileiro. Río de Janeiro: Edições Teatro Experimental do Negro.

Río de Janeiro: Paz e Terra.

Olaniyan, T. (2007). Festival, ritual, and drama in Africa. En Tejumola, O. y Quayson, A. (Eds.). African Literatures: an antology of criticism and theory (pp. 285-306). Richmond: Blackwell Publishing.

Oliveira, A. B. (2004). Canto para os orixás. Río de Janeiro: Pallas.

Oliveira, E. (2006). Cosmovisão africana no Brasil. Curitiba: Gráfica Popular.

Ortiz, F. (1963). Contrapunteo cubano del tabaco y el azúcar. La Habana: Consejo Nacional de Cultura.

Ribeiro, R. (1996). Alma africana no Brasil. Os iorubás. São Paulo: Editora Ododuwa.

Rui, M. (1987). Eu e o outro - O Invasor ou Em poucas três linhas uma maneira de pensar o texto. En Medina, C. (Ed.). Sonha Mamana África (pp. 308-310). São Paulo: Epopéia.

Taylor, D. (mayo sw 2014a). Escenas de cognición: performance y conquista. Recuperado de http://www.casa.cult.cu/publicaciones/revistaconjunto/151/taylor.pdf 
(mayo, 2014b). Hacia una definición de performance. Recuperado de http://132.248.35.1/cultura/ponencias/PONPERFORMANCE/Taylor.html

Zapata Olivella, M. (1989). Las claves mágicas de América. Bogotá: Plaza \& Janés.

Cultura.

(2010a). Changó el gran putas. Bogotá: Ministerio de (2010b). Por los senderos de los ancestros. Bogotá: Ministerio de Cultura.

Zumthor, P. (2007). Performance, recepção, leitura. São Paulo: Cosac Naify. Zwerling, P. (1997). Introdução à poesia oral. São Paulo: Hucitec.

(2004). The Political Agenda for Theatricalizing Religion in Shango de Ima and Sortilege II: Zumbi Returns. Journal of Religion and Theatre, 3(2), pp. 303-316. 